J. Egypt. Soc. Parasitol. (JESP), 51(1), 2021: 189 - 200

(Online: 2090-2549)

\title{
COMMON OPPORTUNISTIC PULMONARY PARASITES IN HIV PATIENTS AND THEIR IMPACT ON ORGAN TRANSPLANTATION
}

\section{By}

YASSER AHMED EL-SAYED ${ }^{1}$ and TOSSON A. MORSY ${ }^{2}$

Consultant of Thoracic Surgery, Military Medical Academy ${ }^{1}$, Cairo, 11291, Egypt, and Department of Parasitology, Faculty of Medicine, Ain Shams University ${ }^{2}$, Cairo 11566 (*Correspondence: yasser.elsaide31@yahoo.com \& morsyegypt2014@gmail.com)

\section{Abstract}

HIV (human immunodeficiency virus) is a virus that attacks the body's immune system, If not treated would lead to AIDS (acquired immunodeficiency syndrome). The HIV infection is acquired from contact with infected blood, semen, or vaginal fluids. Most patients get HIV by having unprotected sex with someone who has HIV. Another common way is by sharing drug needles with HIV infected patient. Most patients develop a pulmonary complication during the history of HIV infection. Lung is the most frequently affected site by the bacterial, fungal, viral and parasitic diseases.

Key words: HIV, Opportunistic parasites, Lung, Human immunity, Organ transplantation, Review.

\section{Introduction}

Prior to the era of potent antiretroviral therapy, parasitic pulmonary infections were more commonly seen than they are today. But, the clinicians still need to be aware of presenting symptoms and signs of these uncommon infections, which may still be diagnosed in the immunosuppressed patient with untreated or drug-resistant HIV infection. HIV-related immunosuppression significantly increases the risk for acquiring opportunistic infections due to bacteria, viruses, fungi, and protozoa. These opportunistic infections are a major source of morbidity and mortality in HIV-infected patients. Substantial advances in the prevention of opportunistic infections have been achieved. These strategies involve prophylactic antibiotics, immunizations, and public health measures. The cost effectiveness of preventing infections is variable, ranging from $\$ 16,000$ per quality adjusted life-year saved for Pneumocystis carinii pneumonia to over $\$ 300,000$ for cytomegalovirus (Freedberg et al, 1998). A total of 33 million people were estimated to be living with HIV/AIDS, and more than 37 million had died since the epidemic begin (UNAIDS, 2009). The HIV patients who are unaware of their diagnosis could in one way or another passively infect others or family members.

\section{Review and Discussion}

The HIV-patients opportunistic pulmonary parasites were mainly Toxoplasma gondii,
Strongyloides stercoralis, Cryptosporidium parvum, Entamoeba histolytica, echinococcosis/hydatidosis, paragonimiasis and others, apart from Aspergillus, Cryptococcus, Histolasma, Microsporidium Coccidioides, Cytomegalovirus, and the clinical manifestations of pneumocystis found elsewhere (Skalski and Limper, 2016).

Toxoplasmosis: Toxoplasma gondii is a ubiquitous intracellular protozoan. Although $T$. gondii can infect a wide range of vertebrates, feral and domestic cats are the definitive hosts. The organism undergoes its complete life cycle in cat, resulting in the production of oocytes, which are passed with the feces into soil (Sabry et al, 2013). T. gondii prevalence in Egyptian feral cats denoted a high oocysts environmental contamination (Al-Kappany et al, 2010). Oocytes may remain infective for over one year and infection is mainly acquired by ingestion of food or water contaminated with oocysts shed by cats or by eating undercooked or raw meat containing tissue cysts or use contaminated knives, cutting boards or other utensils (Montoya and Liesenfeld, 2004), or congenitally mother to fetus (Saleh et al, 2014). Transmission also, occurred by blood transfusion from infected donor (Sarwat et al, 1993), occupational (Saleh et al, 2016) and needle-injury (Abdel-Motagaly et al, 2017). There is no evidence of any other type of man-toman transmission. Barsoum (2004) reported that toxoplasmosis, malaria, trypanosomia- 
sis, and leishmaniasis are the main parasites transmitted with bone marrow, kidney, or liver homograft. Miró et al. (20120 in Spain declared that parasites must be considered in the differential diagnosis of post-transplant infections in foreign-born recipients. Kim et al. (2020) in Korea by DNA analyzed detected $T$. gondii in ticks, but neither associated with tick species nor development stage. Percipalle et al. (2021) in Italy detected traces of $T$. gondii DNA in samples of dehydrated mealworm whose life cycles make them candidates for potential insect breeding substrate contamination. They concluded the need for implementing good farming and processing practices with particular care to safe storage and handling of feed and substrates used for edible insects to reduce $T$. gondii entering the human food chain

Clinical epidemiology: T. gondii is generally believed to cause subclinical infection in most immunocompetent hosts, but one review found that one-third of reported cases of active pneumonia were in patients with no underlying immunosuppressive illness (Pomeroy and Filice, 1992). Of the remaining two-thirds, $61 \%$ had AIDS \& 39\% had other forms of immunosuppression (Mariuz et al, 1994). Most active cases of toxoplasmosis are due to reactivation of latent infection. About one-third of adults in the United States were IgG seropositive for $T$. gondii (Evans and Schwartzman, 1991). In HIVpatients who were seropositive for $T$. gondii was estimated about 30\% developed Toxoplasma encephalitis within 2 years of initial AIDS diagnosis; another 1\% who was seronegative, but developed primary toxoplasmosis (Holliman, 1990).

Generally, toxoplasmosis is a serious and often life-threatening disease in immunodeficient patients. Although encephalitis is overwhelmingly the commonest manifestation of $T$. gondii infection in AIDS patients, pneumonitis has become its second most common presentation. Incidence of pneumonitis is unknown, but number of cases is in- creasing. The estimated prevalence of $T$. gondii pneumonia in France was 5\%, based upon a prospective study of bronchoalveolar on a prospective study of bronchoalveolar lavage (BAL) specimens in 169 AIDS patients. Rates in the United States were much lower, which may be due to lower rates of dormant infection or to under-diagnosis. Active pulmonary toxoplasmosis did not occur in HIV-infected patients until CD4+ count falls $<100$ cells/mm3 (Derouin et al, 1990).

Clinical presentation: Toxoplasma pneumonitis generally presents with fever, nonproductive cough, and dyspnea. The chest radiographs generally show diffuse bilateral interstitial and alveolar infiltrates. Other abnormalities include single or bilateral pulmonary nodules, cavitary infiltrates, lobar pneumonia, and pleural effusions (Bonilla and Rosa, 1994). Pulmonary toxoplasmosis may be clinically indistinguishable from PCP, tuberculosis, cryptococcosis, or histoplasmosis.

Serologic tests for IgG, IgM, IgA, \& IgE to $T$. gondii are available, but results are not always helpful in profoundly immunosuppressed patient. However, the absence of IgG antibody level to $T$. gondii did make the diagnosis much less likely, since most active disease is due to reactivation of latent infection. Gallium scans in patients with $T$. gondii pneumonitis were rare, but diffuse intense uptake was reported, and serum LDH levels markedly elevated (Pugin et al, 1992).

Diagnosis: Bronchoscopy with bronchialveolar lavage (with or without transbronchial biopsy) was the preferred diagnostic method, but its sensitivity and specificity were unknown (Oksenhendler et al, 1990). Diagnosis was confirmed by observing the tachyzoite form of the organism in the BAL fluid or transbronchial biopsy. The reliable diagnostic methods are Giemsa stained or eosin/ methylene blue stains. Tachyzoite is crescent-shaped 5 to 7 microns in length. Immunofluorescence staining with a monoclonal antibody, inoculation of mice followed by traditional culture, or PCR increased the yie- 
ld of BAL, but most of these methods were not available (Derouin et al, 1989).

If bronchoscopy is not diagnostic, then an open lung biopsy can be performed, either by video-assisted thoracoscopic surgery or traditional thoracotomy. Pathologically, a fibrinous exudate can be seen in the bronchi and alveoli, with an inflammatory cell interstitial infiltrate and areas of parenchymal necrosis. Organism may be seen within alveolar macrophages or freely floating within the alveoli. But, diagnosis of Toxoplasma pneumonitis was usually made by postmortem examination of the lungs, because it is often not considered premortem and with the lack of special stains for diagnosis, a review estimated mortality to be $40 \%$ in immunosuppressed hosts (Burg et al, 1989).

Treatment: Most healthy people don't require treatment. But, if health one otherwise with signs and symptoms of acute toxoplasmosis, his doctor may prescribe the following drugs: Pyrimethamine (Daraprim ${ }^{\circledR}$ ) typically used for malaria is a folic acid antagonist. Other potential side effects of pyrimethamine include bone marrow suppression and liver toxicity. Also, Sulfadiazine ${ }^{\circledR}$ was used with pyrimethamine to treat children toxoplasmosis (Wishahy et al, 1972). The combination of Pyrimethamine and Sulfadiazine is the regimen of choice for treatment of extrapulmonary toxoplasmosis. This regimen was used for pulmonary toxoplasmosis as there were no controlled studies specifically designed for lung infection. A 200mg loading dose of pyrimethamine was given initially and followed by 50 to $75 \mathrm{mg} /$ day, but sulfadiazine was given at 4 to $6 \mathrm{gm} /$ day (McCabe and Oster, 1989). Leucovorin calcium (10 to $20 \mathrm{mg} /$ day orally) usually given to reduce hematologic toxicity of these drugs. Clindamycin (in dose of $600 \mathrm{mg}$ every $6 \mathrm{hrs}$.) was used combined with pyrimethamine in patients with sulfa intolerance. Treatment time of toxoplasmosis pneumonitis was unknown, however, at least three to six weeks was given, depending upon the disease severity and the response rate (Dannemann et al, 1992).
The acute toxoplasmosis during pregnancy is detrimental to the developing fetus. Thus, treating pregnant women and babies varied. If infection occurred before the $16^{\text {th }}$ week of pregnancy, spiramycin ${ }^{\circledR}$ was recommended, which may reduce fetus's risk of neurological problems, but if occurred after the $16^{\text {th }}$ week of pregnancy, or fetus had toxoplasmosis, pyrimethamine and sulfadiazine and folinic acid (leucovorin) was recommended. Besides, prenatal care must include health education about prevention of toxoplasmosis (Paquet and Yudin, 20180). Other drugs included atovaquone, azithromycin, clarithromycin, dapsone, pyrimethamine or trimethoprim-sulfamethoxazole alone or in combination with others (Dunay et al, 2018).

Some studies suggest successful treatment outcomes in 50 to $77 \%$ of patients, although the number of cases of pulmonary toxoplasmosis is small (Maguire et al, 1986).

Secondary prophylaxis: Secondary prophylaxis or maintenance therapy is prudent because relapses of toxoplasmosis are reported in up to $80 \%$ of patients after successful treatment (Lane et al, 1994). The lowest Toxoplasma encephalitis relapse rate was reported with Pyrimethamine ( 25 to $75 \mathrm{mg} /$ day) \& sulfadiazine (1.0 to $1.5 \mathrm{gm}$ four times daily) with Leucovorin (15mg/day). Clindamycin with Pyrimethamine can be used in sulfa intolerant patients. There was, however, a high relapse rate with low doses of Clindamycin; as a result, $1200 \mathrm{mg} /$ day in divided doses is suggested if tolerated by the patient (Luft and Remington, 1992).

According to guidelines issued by CDC, and the Infectious Diseases Society of America, discontinuation of secondary prophylaxis was considered if the patient successfully completed treatment, asymptomatic and CD4 count was maintained above 200cells/ microL for six months (Benson et al, 2005).

Primary prophylaxis: Primary prophylaxis against Toxoplasma encephalitis should be considered in patients with CD4+ counts below $100 \mathrm{cell} / \mathrm{mm} 3$ and positive $T$. gondii serology. TMP/SMX is the recommended first- 
line prophylactic agent, as it also gave prophylaxis against PCP. Other effective prophylactic drugs include pyrimethamine as a single agent, pyrimethamine-dapsone, fansidar, as well as clarithromycin, azithromycin, and atovaquone (Furrer et al, 2000).

Seronegative persons who are not taking a PCP prophylactic agent with known activity against toxoplasmosis should be retested for IgG antibody when their CD4+ count drops below 100 cells $/ \mathrm{mm} 3$. They should receive appropriate prophylaxis if they have seroconverted (CDC, 1995). If the CD4 count rises above 200 cells/microL for three months, primary prophylaxis for toxoplasmosis may be discontinued (Mussini et al, 2000).

Strongyloidiasis: Strongyloides stercoralis is an intestinal parasite that has a worldwide distribution. Low estimates postulate it to affect 30-100 million people worldwide mainly in the tropical and subtropical countries (Buonfrate et al, 2015), while higher estimated conservatively extrapolate that infection is upwards to or above 370 million people (Varatharajalu and Kakuturu, 2016), but was predominantly found in the tropical and subtropical areas as well as the southeastern United States (Grove, 1989). The primary mode of transmission occurred when larvae from contaminated feces penetrate the skin, although infection can also occur via the fecal-oral route and from sexual transmission (Jaleta et al, 2017). Most infected persons remain either asymptomatic or have low grade abdominal symptoms. Some patients, particularly those who were immunosuppressed, could develop disseminated strongyloidiasis or hyperinfection syndrome, both of which were considered as systemic strongyloidiasis (Satoh et al, 2003). The free cycle of Strongyloides allowed them for residency in the lungs (Viney, 2006). Strongyloidiasis dissemination occurred when chronic strongyloidiasis patients became immunosuppressed or when the larval form was found outside the usual migration pattern. Hyper-infection is an augmentation of life cycle, resulted in heavy worms' lung infections (Lessnau et al, 1993). The hyper-infection of various levels of severe dissemination may present with abdominal pain, distensions, shock, pulmonary and neurologic complications, sepsis, hemorrhage, malabsorption, and depending on the combination, degree, number, and severity of symptoms, was fatal (Arthur and Shelley, 1958). Worms enter bloodstream via bowel wall, simultaneously allowed entry of bowel bacteria such as Escherichia coli (Ghoshal et al, 2002), which caused symptoms such as sepsis to bloodstream infection (Graeff-Teixeira et al, 2002), or bacteria spread to other organs where they caused localized infection as meningitis (El-Bahnasawy et al, 2016). Wołyniec et al. (2018) found that solid organ and bone marrow (toxoplasmosis, malaria, \& leishmaniasis) transplantations, blood transfusions and immunosuppressive treatment were associated with a small, but real risk of giardiasis and cryptosporidiosis causing diarrhea in the European Citizens. Fürnkranz and Walochnik (2021) in Austria reported nosocomial S. stercoralis transmission by organ transplantation

Clinical manifestations: Majority of strongyloidiasis infected people do not have symptoms. Those who developed symptoms often have non-specific, or generalized complaints, as abdominal pain, bloating, heartburn, intermittent episodes of diarrhea and constipation, a dry cough, vomiting, and weight loss, red hives near the anus, and skin rashes. The acute manifestations are associated with the pre-patent period, defined as the time from penetration of infective larvae to production of new larvae by a mature female adult (Freedman, 1991). Infected individuals frequently experience irritation at the site of skin penetration that appears immediately followed occasionally by localized edema or urticaria that could last up to 3 weeks. Urticaria particularly involving the perianal skin and buttocks were the commonest chronic strongyloidiasis symptom (O'Brien, 1975). Within a week following infection, a dry cough may occur. Gastrointestinal symptoms such as diarrhea, constipation, abdominal 
pain or anorexia can occur following the infection establishment in the small intestine as early as the $3^{\text {rd }}$ week of infection (Keiser and Nutman, 2004). Once larval production by adults starts $(\sim 1$ month following initiation of infection) new cycles of infection can be initiated through autoinfection (whether within the intestinal mucosa or in perianal skin) that often presents as a non-specific urticarial rash or pathognomonic larva currens (Gaus et al, 2011). Barsoum (2004) in Egypt reported that strongyloidiasis was among the parasites reactivated in the immunocompromised host (organ transplantation).

Clinical epidemiology: Surprisingly, there have been scattered cases of systemic strongyloidiasis in HIV-infected patients (Maayan et al, 1987). The only associated risk factor in the HIV-infected population is previous or current residence in an endemic area. Risk factors for the strongyloidiasis development in the general population include: Race (white) Gender (male) Use of steroids Hematologic malignancy Prior gastric surgery (Davidson et al, 1984). Moreover, the presence of co-infection with schistosomiasis or ascariasis may be an additional risk factor that was relevant in rural, underdeveloped countries where these infections were common (Nucci et al, 1995).

Clinical presentation: Systemic strongyloidiasis is manifested by fever, malaise, and gastro-intestinal \&/or respiratory symptoms. Eosinophilia is common in immunocompetent patients with chronic strongyloidiasis, but it may be absent in immunocompromised patients who develop systemic strongyloidiasis. Eosinopenia was a poor prognostic indicator as Gram negative bacteremia and meningitis may complicate these infections (Igra-Siegman et al, 1981).

Diagnosis: The organisms may be identified through examination of wet preparations of stool, sputum, or bronchoalveolar lavage fluid. Diagnosis may also be made serologically, but the tests were not widely available: ELISA has a sensitivity of 85 to $90 \%$ and a specificity of $90 \%$. However, there were false positive tests in patients with other parasitic infections (Celedon et $a l, 1994)$. Serial antibody titers may be followed in patients who have been treated, but with some difficulties in distinguishing acute from previous infection.

Treatment: Ivermectin $(200 \mathrm{mcg} / \mathrm{kg} / \mathrm{day})$ is the first-line agent for treatment, and a course of 5 to 7 days was suggested in immunosuppressed patients with systemic disease. But, ivermectin did not kill the larvae, only adults; therefore repeat dosing was necessary to properly eradicate the infection and auto-infective cycle of roughly two weeks (Repetto et al, 2018). Lifelong suppressive therapy may be indicated for both gastrointestinal and pulmonary infections in patients with relapses (Igual-Adell et al, 2004). Other effective strongyloidiasis drugs are Albendazole \&Thiabendazole $(25 \mathrm{mg} / \mathrm{kg}$ twice daily for 5 days to $400 \mathrm{mg}$ maximum (Gompels et al, 1991). Massoud et al. (2006) in Egypt treated 28 parasitological proved strongyloidiasis male patients (18-65 years old) with Mira$\mathrm{zid}^{\circledR}$ given for one month except three resistant cases. One of them responded to repeated course of Mirazid, while the other two cases still had larvae in their stool by agar culture plate. On combined therapy of both Mirazid \& Mebendazole ${ }^{\circledR}$, larvae were eliminated from their stool as approved by agar plate culture.

Empiric therapy: Prophylaxis should be considered in patients from endemic areas, especially those with unexplained eosinophilia. Ivermectin was given as a single dose $(200 \mathrm{mcg} / \mathrm{kg} / \mathrm{day})$ or a multi-dose schedule (200mcg/kg/day for four days). Remissions induced by the multi-dose regimen of ivermectin were maintained for up to 3 years (Torres et al, 1993).

Entamoeba histolytica: Amebic liver abscess always preceded lung infections; early diagnosis and treatment prevent complications (Del Campo and Del Campo, 1982). Invasive amebiasis was more common in immunosuppressed, pregnant women, children, and alcoholics. Pleuropulmonary form occ- 
urred exclusively with complications included right-sided sympathetic effusions, empyema, basilar atelectasis, lung infiltration, \& abscess (Lyche and Jensen, 1977). Shamsuzzaman and Hashiguchi (2002) in Japan detected Acanthamoeba, a free-living ameba, infected the lungs forming pulmonary nodular infiltration and edema in association with amebic meningoencephalitis in immunocompromised patients. They concluded that HIV/AIDS patients were not prone to $E$. histolytica infection and that minimal incidence of intestinal infection among HIV-seropositive or AIDS patients did not mean any more amebiasis invasive.

Echinococcosis/hydatidosis: Echinococcus granulosus and E. multilocularis are the commonest organisms responsible for pulmonary hydatid cysts (Polat et al, 2003) of worldwide distribution (Schwartz, 1994). Dogs stray (Sarkari and Rezaei, 2015) or pet ones (Sabry et al, 2012) as well as other carnivores are the definitive hosts. All vertebrate mammals including man are the intermediate hosts (Eckert and Deplazes, 2004). Iyigun et al. (2004) considered hydatidosis an occupational infectious disease. Hydatidosis is acquired by ingesting echinococcosis eggs in food or water or by close contact with an infected dogs, foxes and wolves (Turkyilmaz et al, 2004). Hydatid cysts consist of three layers, pericyst, ectocyst, and endocyst, which can be ruptured or un-ruptured (Haridy et al, 2008). Human lungs were the second most common organ of involvement in adults, after the liver (Wilson, 1991). Hydatidosis of organs outside of liver or lung were unusual as CNS (Mazyad et al, 1999), heart, kidney, bone and ocular (Gogus et al, 2003), brain (Farahmand et al, 2010), ovary causing ovarian neoplasm (Sharma et al, 2012), pancreas (Akbulut et al, 2014), pelvic (Bhatnagar et al, 2017), breast (Temiz et al, 2017), uterus (Kakaei et al, 2017), foot (Ewnte, 2020), or even anal fossa (Abdalla et al, 2020). However, lungs were the most common site of involvement in children (Polat et al, 2003). Un-ruptured hydatids on CT appeared as well demarcated spherical or oval homogeneous cystic lesions with enhancing walls in the lung, more commonly in mid and lower zones (Pedrosa et al, 2017). Daughter cysts may be seen as curved septations within it, but calcification was rare in pulmonary hydatid cysts (El-Sayed et al, 2020). Cyst rupture can also lead to secondary infection or lung abscess formation with a type of liquefactive necrosis of lung tissue and formation of cavities (more than $2 \mathrm{~cm}$ ) containing necrotic debris or fluid caused by microbial infection (Kuhajda et al, 2015).

Alveolar echinococcosis (AE) was a rare but potentially life-threatening infection due to the accidental ingestion of the egg of the parasite Echinococcus multilocularis. It is encountered only in the northern hemisphere (Wen et al, 2019). Its natural history is characterized by a slow parasitic growth over several years, as Immunomodulation of host immunity toward energy was triggered by parasite metabolites (Gottstein et al, 2015). Dupont et al. (2020) reported an exceptionally fast growing and aggressive E. multilocularis in a 41-year old Caucasian female veterinarian who underwent a right lung transplantation (LT) for pulmonary fibrosis, and Ten months after transplantation, irregular hepatomegaly was detected associated with persisting pain in the right hypochondrium. They concluded that clinicians dealing with immunosuppressed patients living in endemic areas should not only be aware of the need to search for preexisting lesions, but also help prevent new cases of infections.

Treatment: Sayek et al. (2004) in Turkey mentioned that although certain types of hydatid cysts were successfully treated by percutaneous aspiration, injection, and reaspiration, treatment of choice is surgery. Thapa et al. (2018) in United Kingdom reported that controversies about the best surgical technique, complications brought on by cyst rupture, multiplicity and multi-organ involvement add complexity to treatment decisions. El-Sayed et al. (2020) in Egypt successfully used staging surgery for patient with bilateral 
pulmonary cyst or pulmonary and liver cysts. Albendazole in dose $10 \mathrm{mg} / \mathrm{kg} /$ day was given pre- and post-operative. Also, Ibrahim and Morsy (2020) reported that both PAIR and laparoscopic procedure were recommended as staging treatment surgery of liver hydatidosis, with albendazole $10 \mathrm{mg} / \mathrm{kg} / \mathrm{d}$ was given as prophylaxis during PAIR technique.

Paragonimiasis is a foodborne parasite caused by the lung fluke, most commonly Paragonimus westermani infecting about $22 \mathrm{mi}-$ llion people yearly worldwide (Lane et al, 2009). Acute phase (invasion and migration) caused diarrhea, abdominal pain, fever, cough, urticaria, hepatosplenomegaly, pulmonary abnormalities, and eosinophilia. In chronic phase, pulmonary manifestations included cough, expectoration of discolored sputum containing clumps of eggs (CDC, 2013). Pozio (1991) in Western Africa reported human paragonimiasis (2 to 31\%).Diaz (2011) in USA reported paragonimiasis after eating raw crayfish. Song et al. (2011) in Korea reported that surgeons must include paragonimiasis in differential diagnosis of asymptomatic nodular lesions in patients' lungs. Field et al. (2018) in Canada reported that cough is common in pulmonary TB and other chronic respiratory infections due to mycobacteria, fungus, and paragonimiasis.

Cryptosporidium is causative agents of gastrointestinal disease in HIV-infected patients (Mannheimer and Soave, 1994). Lung disease due to Cryptosporidium was reported in the early AIDS era, before anti-riretroviral therapy, and fever and cough were the dominant symptoms (Forgacs et al, 1983).

Cryptosporidium is a microscopic parasite that causes the diarrheal disease cryptosporidiosis. Both the parasite and the disease are commonly known as "Crypto." By genotypes within Cryptosporidium isolates showed about 20 species (Robinson et al, 2008). Cryptosporidium species infect all the vertebrates including mammals, reptiles, birds, and fish, some of which also infect humans (Sponseller et al, 2014). C. parvum was divided into two separate species: $C$. hominis (previously $C$. parvum genotype 1 ) and $C$. parvum (formerly C. parvum genotype 2 ). $C$. hominis apparently infects only man, and $C$. parvum was found in many animals and in man (Morgan-Ryan et al, 2002). Animal cryptosporidiosis as C. canis, C. felis, C. meleagridis, $C$. muris, and $C$. suis were reported in some patients (Cacciò, 2005). Pathogenic agents was associated with $C$. parvum were Cyclospora cayetanensis Microsporidium and cytomegalovirus (Teixidor et al, 1991).

People at risk: many people are at exposure risks: 1- People who swim regularly in pools with insufficient sanitation, as certain Cryptosporidium strains are chlorine-resistant (CDC, 2009). 2- The person-to-person transmission is common particularly among family members, sexual partners, children in daycare centers (Musher and Musher, 2004). 3- Nursing of cryptosporidiosis pati-ents. 4People consuming contaminated water from unfiltered or untreated sources as well as contaminated raw vegetables or fruits (Ethelberg et al, 2009). 5- Farmers and visitors visiting petting farms and open farms with public access (Walker, 2018), an outbreak of cryptosporidiosis was reported among firefighters responded to a fire in the barn housing calves, where many waterbor-ne outbreaks were reported (CDC, 2012). 6- People exposed to human feces (fecal-oral), as well as insertive anal sex (Black et al, 2003) and oral-genital sex (Borchardt and Noble, 1997). 7- Respiratory transmission might arise if oocysts were aerosolized during coughing (Højlyng et al, 1987), and 8- People exposed to human feces.

Prevention: Cryptosporidium is resistant to chlorine disinfection, so it is tougher to be killed than most disease-causing germs. The usual disinfectants, including most commonly used bleach solutions gave little effect on the parasite. An application of hydrogen peroxide was the best (Chalmers et al, 2019).

Blood parasites: babesiosis and malaria are parasites of worldwide distribution. Babesiosis is transmitted by hard-ticks, and malaria by female Anopheles. Also, both are transm- 
itted by blood transfusion, needle-stick injury and congenitally. Some Babesia species cause potentially fatal disease in many mammalian species including man. it causes hemolysis accounting for clinical complications as hemolytic anemia, cardiorespiratory /renal failure, disseminated intravascular coagulation and even death (Vannier and Krause, 2012). Malaria (Plasmodium falciparum, $P$. vivax, $P$. malariae, $P$. ovale, and $P$. knowlesi), is a risky human disease. The major clinical complications are severe anemia, cerebral malaria, placental malaria, acute renal failure and acute lung injury/acute respiratory distress (Taylor et al, 2012). Pulmonary edema due to increased pulmonary capillary permeability is the risky pulmonary manifestation (Adam and Elbashir, 2004).

Also, visceral leishmaniasis (VL) is a severe, systemic and potentially lethal parasites. Lung, like any other organ, can be affected in VL, and interstitial pneumonitis was described in past decades (Morsy, 1997). Typical manifestations include fever, weight loss, hepatosplenomegaly, and pancytopenia resulting from Leishmania amastigotes replication in macrophages mainly in liver, spleen, and bone marrow, but as splenomegaly may be absent in VL/HIV-co-infected patients, but atypical organ involvement, such as of lungs or gastrointestinal system (Bispo et al, 2020). Amyloid A (AA) amyloidosis leading to renal failure was associated with chronic VL in HIV patients

Prevention of HIV is spread by having sex or sharing syringes and other injection equipment with HIV infected someone. Substance use can contribute to these risks indirectly because alcohol and other drugs can lower people's inhibitions and make them less likely to use condoms (CDC, 2020).

\section{Conclusion}

Generally speaking, human immunodeficiency viruses are two species of Lentivirus (a subgroup of retrovirus) that infect human. Over time, they cause acquired immunodeficiency syndrome (AIDS), a condition in which progressive failure of immune sys- tem allows life threatening opportunistic infections and cancers to thrive. Without treatment, average survival time after HIV infection was about 9 to 11 years, depended on the HIV subtype. Lungs provide a protected environment for the survival of vulnerable stages of some parasites development, which were omnipresent and exerted persistent selective pressure on the human immune response. Invasive parasites including lung ones are increasing in HIV patients. Patients with immunodeficiency syndromes (HIV infection, organ transplantation and immunosuppressive drugs; as corticosteroids) must be evaluated for early diagnosis of lung parasites and proper treatment. No doubt, respiratory diseases are a risky cause of morbidity and mortality.

\section{References}

Abdalla, KM, Al Sharie, AH, ALzu'bi, YO, Daoud, MN, Aleshawi, AJ, et al, 2020: Ischioanal fossa hydatid cyst. Int. J. Infect. Dis. 92: 181-3.

Abdel-Motagaly, AME, Ibrahim, AMA, Morsy, TA, 2017: An intervention program on blood protozoa acquired by needle stick injury and infection control. J. Egypt. Soc. Parasitol. 47, 2: 309-22

Adam, I, Elbashir, MI, 2004: Maternal death due to severe pulmonary oedema caused by falciparum malaria: a case report. East. Mediterr.

Hlth. J. 10, 4/5:685-7.

Akbulut, S, Yavuz, R, Sogutcu, N, Kaya, B, Hatipoglu, S, et al, 2014: Hydatid cyst of the pancreas: Report of an undiagnosed case of pancreatic hydatid cyst and brief literature review. World J. Gastrointest. Surg. 6, 10:190-200

Al-Kappany, YM, Rajendran, C, Ferreira, L R, Kwok, OC, Abu-Elwafa, SA, et al, 2010: High prevalence of toxoplasmosis in cats from Egypt: Isolation of viable Toxoplasma gondii, tissue distribution, and isolate designation. J. Parasitol. 96, 6:1115-8

Arthur, RP, Shelley, WB, 1958: Larva currens: A distinctive variant of cutaneous larva migrans due to Strongyloides stercoralis. AMA Arch. Dermatol. 78, 2:18-21

Barsoum, RS, 2004: Parasitic infections in organ transplantation. Exp. Clin. Transplant. 2, 2: 258-67.

Benson, CA, Kaplan, JE, Masur, HC, et al, 
2005: Treating opportunistic infections among HIV-infected adults and adolescents: Recommendations from CDC, the NIH, \& HIV Medicine Association/Infectious Diseases Society of America. Clin. Infect. Dis. 40:S131.

Bhatnagar, N, Kishan, H, Sura, S, Lingaiah, P, Jaikumar, K, 2017: Pelvic hydatid disease: A case report and review of literature. J. Orthop. Case Rep. 7:25-8

Bispo, AJB, Almeida, MLD, de Almeida, RP, Bispo, NJ, de Oliveira Brito, AV, et al, 2020: Pulmonary involvement in human visceral leishmaniasis: Clinical and tomographic evaluation. PLoS One Jan 30;15(1):e0228176.

Black, ER, Mushlin, AI, Griner, PF, Suchman, AL, James, RL, et al, 2003: Predicting the need for hospitalization of ambulatory patients with pneumonia. J. General Inter. Med. 6, 5:394400.

Bonilla, CA, Rosa, UW, 1994: Toxoplasma gondii pneumonia in patients with the acquired immuno-deficiency syndrome: Diagnosis by bronchoalveolar lavage. South Med. J. 87:659-63.

Borchardt, KA, Noble, MA, 1997: Sexually Transmitted Diseases: Epidemiology, Pathology, Diagnosis, and Treatment. CRC Press.

Buonfrate, D, Formenti, F, Perandin, F, Bisoffi, Z, 2015: Novel approaches to the diagnosis of Strongyloides stercoralis infection. Clin. Microbiol. Infect. 21, 6:543-52

Burg, JL, Grover, CM, Pouletty, P, Boothroyd, JC, 1989: Direct and sensitive detection of a pathogenic protozoan, Toxoplasma gondii, by polymerase chain reaction. J. Clin. Microbiol. 27:1787-92.

Cacciò, SM, 2005: Molecular epidemiology of human cryptosporidiosis. Parassitologia 47:18592.

CDC, 1995: USPHS/IDSA guidelines for the prevention of opportunistic infections in persons' infected with human immunodeficiency virus: A summary. MMWR Morb. Mortal. Wkly. Rep. 44:1.

CDC, 2009: Outbreak of cryptosporidiosis associated with a splash park-Idaho, 2007. MMWR Morb. Mortal. Wkly. Rep. 58:615.

CDC, 2012: Outbreak of cryptosporidiosis associated with a firefighting response: Indiana and Michigan, June 2011. MMWR Morb. Mortal. Wkly. Rep. 61:153.

CDC, 2013: Paragonimiasis, clinical features. Archived from retrieved 2012-09-06.

CDC, 2020: HIV Risk and Prevention. Advanc- ced Research.

Celedon, JC, Mathur-Wagh, U, Fox, J, et al, 1994: Systemic Strongyloides in patients infected with the human immunodeficiency virus. Medicine 73:256-60.

Chalmers, RM, Davies, AP, Tyler, K, 2019: Cryptosporidium. Microbiology (Reading) 165, 5:500-2

Dannemann, B, McCutchan, JA, Israelski, D, et al, 1992: Treatment of toxoplasmic encephalitis in patients with AIDS, a randomized trial comparing pyrimethamine plus clindamycin to pyrimethamine plus sulfadiazine. Ann. Intern. Med. 116:3-8.

Davidson, RA, Fletcher, RH, Chapman, LS, 1984: Risk factors for Strongyloides: A case-control study. Arch. Intern. Med. 144:321-6.

Del Campo, C, Del Campo, M, 1982: Thoracic complications of amebiasis. Can. J. Surg. 25, 2: 119-21.

Derouin, F, Sarfati, C, Beauvais, B, et al, 1989: Laboratory diagnosis of pulmonary toxoplasmosis in patients with acquired immunodeficiency syndrome. J. Clin. Microbiol. 27:1661-8.

Derouin, F, Sarfati, C, Beauvais, B, et al, 1990: Prevalence of pulmonary toxoplasmosis in HIV-infected patients. AIDS 4:1036-42.

Diaz, JH, 2011: Boil before eating: Paragonimiasis after eating raw crayfish in the Mississippi River Basin. J. La State Med Soc. 163, 5:261-6. Dunay, IR, Gajurel, K, Dhakal, R, Liesenfeld, O, Montoya, J, 2018: Treatment of toxoplasmosis: Historical perspective, animal models, and current clinical practice. Clin. Microbiol. Rev. 31, 4:e00057-17.

Dupont, C, Grenouillet, F, Mabrut, JY, Gay, F, Persat, F, et al, 2020: Fast-growing alveolar echinococcosis following lung transplantation, Pathogens. 9(9):756.https://doi.org/10.3390/pathogens 9090756.

Eckert, J, Deplazes, P, 2004: Biological, Epidemiological, and Clinical Aspects of Echinococcosis, a Zoonosis of Increasing Concern. Clin. Microbiol. Rev. 17, 1:107-35.

El-Bahnasawy, MMN, El Feky, MR, Morsy, ATA, Ismail, MAM, Morsy, TA, 2016: Egyptian eosinophilic and infectious meningoencephalitis \&their impact on psychological aspects. J. Egypt. Soc. Parasitol. 46, 1:67-80.

El-Sayed, YA, Ibrahim, EA, Morsy, TA, 2020: Peri-cystectomy versus cystotomy and enucleation of germinal layer by tissue spearing technique for lung hydatid in Egypt. J. Egypt. Soc. 
Parasitol. 50, 3:494-503.

Ethelberg, S, Lisby, M, Vestergaard, LS, et al, 2009: A foodborne outbreak of Cryptosporidium hominis infection. Epidemiol. Infect. 137:348-52 Evans, GT, Schwartzman, JD, 1991: Pulmonary toxoplasmosis. Semin. Respir. Infect. 6:51-8. Ewnte, B, 2020: Hydatid cyst of the foot: A case report. J. Med. Case Rep. 14, 1:6. doi:10. 1186/

Farahmand, M, Yadollahi, M, 2010: Echinococcosis: An occupational disease. Int. J. Occup. Environ. Med. 1, 2:88-91.

Field, SK, Escalante, P, Fisher, DA, Ireland, B, Irwin, RS, 2018: Cough due to tb and other chronic infections: Chest guideline and expert panel report. Chest 153, 2:467-97.

Forgacs, P, Tarshis, A, Ma, P, et al, 1983: Intestinal and bronchial cryptosporidiosis in an immuno-deficient homosexual man. Ann. Intern. Med. 99:793-5.

Freedberg, KA, Scharfstein, JA, Seage, GA, et al, 1998: The cost effectiveness of preventing AIDS-related opportunistic infections. JAMA 279:130-6.

Freedman, DO, 1991: Experimental infection of human subject with Strongyloides species, a review. Rev. Infect. Dis. 13, 6:1221-6.

Fürnkranz, U, Walochnik, J, 2021: Nosocomial infections: Do not forget the parasites! Pathogens 10, 2:238. doi:10.3390/10020238.

Furrer, H, Opravil, M, Bernasconi, E, et al, 2000: Stopping primary prophylaxis in HIV-1 infected patients at high risk of toxoplasma encephalitis: Swiss HIV Cohort Study. Lancet 355: 2217-21.

Gaus, B, Toberer, F, Kapaun A, Hartmann, M, 2011: Chronic Strongyloides stercoralis infection: Larva currens as skin manifestation. Hautarzt 62, 5:380-3.

Ghoshal, UC, Ghoshal, U, Jain, M, Kumar, A, Aggarwal, R, et al, 2002: Strongyloides stercoralis infestation associated with septicemia due to intestinal transmural migration of bacteria. J. Gastroenterol. Hepatol. 17, 12:1331-3.

Gogus, C, Safak, M, Baltaci, S, Turkolmez, K, 2003: Isolated renal hydatidosis: Experience with 20 cases. J. Urol. 169:186.

Gompels, MM, Todd, J, Peters, BS, Main, J, Pinching, AJ, 1991: Disseminated strongyloidiasis in AIDS: Uncommon but important. AIDS 5, 3:329-32.

Gottstein, B, Wang, J, Boubaker, G, Marinova, I, Spiliotis, M, et al, 2015: Susceptibility ve- rsus resistance in alveolar echinococcosis (larval infection with Echinococcus multilocularis).

Vet. Parasitol. 213:103-9

Graeff-Teixeira, C, da Silva, AC, Yoshimura, K, 2009: Update on eosinophilic meningoen-cephalitis and its clinical relevance. Clin. Microbiol. Rev. 22, 2: 322-48.

Grove, DI, 1989: Strongyloidiasis: A Major Roundworm Infection of Man. Philadelphia, PA: Taylor \& Francis.

Haridy, FM, Abou Holw, SA, Hassan, AA, Morsy, TA, 2008: Cystic hydatidosis: A zoonotic silent health problem. J. Egypt. Soc. Parasitol. 38, 2:635-44.

Højlyng, N, Anderson, W, Jepson, S, 1987: Cryptosporidiosis: A case of airborne transmission. Lancet 2:271-2.

Holliman, RE, 1990: Serological study of the prevalence of toxoplasmosis in asymptomatic patients infected with human immunodeficiency virus. Epidemiol. Infect.105:415-9.

Ibrahim, EA, Morsy, TA, 2020: Tissue sparing technique in liver hydatid diseases: Three-way technique versus hydatid cone technique. J. Egypt. Soc. Parasitol. 50, 2:378-89.

Igra-Siegman, Y, Kapila, R, Sen, P, et al, 1981: Syndrome of hyperinfection with Strongyloides stercoralis. Rev. Infect. Dis. 3:397-400.

Igual-Adell, R, Oltra-Alcaraz, C, Soler, E, et al, 2004: Efficacy and safety of ivermectin and thiabendazole in the treatment of Strongyloides. Expert. Opin. Pharmacother. 5: 2615-20.

Iyigun, O, Uysal, S, Sancak, R, Hokelek, M, Uyar, Y, et al, 2004: Multiple organ involvement hydatid cysts in a 2 -year-old boy. J. Trop. Pediatr. 250, 6:374-6

Jaleta, TG, Zhou, S, Bemm, FM, Schär, F, Khieu, V, et al, 2017: Different but overlapping populations of Strongyloides stercoralis in dogs and humans-dogs as a possible source for zoonotic strongyloidiasis. PLoS Negl. Trop. Dis. 11, 8: e0005752.

Kakaei, F, Asvadi Kermani, T, Tarvirdizade, K, 2017: A case report: Primary hydatid cyst of uterus. Int. J. Surg. Case Rep. 42:67-9.

Keiser, PB, Nutman, TB, 2004: Strongyloides stercoralis in the immunocompromised population. Clin. Microbiol. Rev. 17, 1:208-17.

Kim, JY, Kwak, YS, Lee, IY, Yong, TS, 2020: Molecular detection of Toxoplasma gondii in Haemaphysalis ticks in Korea, Kor. J. Parasitol. 58, 3:327-31.

Kuhajda, I, Zarogoulidis, K, Tsirgogianni, K, 
et al, 2015: Lung abscess-etiology, diagnostic \& treatment options. Ann. Trans. Med. 3, 13:183-9. Lane, HC, Laughon, BE, Falloon, J, et al, 1994: NIH Conference. Recent advances in the management of AIDS-related opportunistic infections. Ann. Intern. Med. 120:945-52.

Lane, MA, Barsanti, MC, Santos, CA, Yeung, M, Lubner, SJ, et al, 2009: Human paragonimiasis in North America following ingestion of raw crayfish. Clin. Infecti. Dis. 49, 6:e55-61

Lessnau, K, Can, S, Talavera, W, 1993: Disseminated Strongyloides stercoralis in human immunod-eficiency virus-infected patients. Chest 104:119-24.

Luft, BJ, Remington, JS, 1992: Toxoplasmic encephalitis in AIDS. Clin. Infect. Dis. 15:2118.

Lyche, KD, Jensen, WA, 1997: Pleuropulmonary amebiasis. Semin. Respir. Infect. 12, 2:10612.

Maayan, S, Wormser, G, Widerhorn, J, et al, 1987: Strongyloides stercoralis hyperinfection in a patient with the acquired immune deficiency syndrome. Am. J. Med. 83:945-50.

Maguire, GP, Tatz, J, Giosa, R, Ahmed, T, 1986: Diagnosis of pulmonary toxoplasmosis by bronchoalveolar lavage. N Y State J. Med. 86: 204-8.

Mannheimer, SB, Soave, R, 1994: Protozoal infections in patients with AIDS: Cryptosporidiosis, isosporiasis, cyclosporiasis, and microsporidiosis. Infect. Dis. Clin. North Am. 8:483-7.

Mariuz, P, Bosley, EM, Luft, BJ, 1994: Toxoplasmosis in individuals with AIDS. Infect. Dis. Clin. 8:365-0.

Massoud, AM, El-Shazly, AM, Awad, SE, Morsy, ATA, Sadek, GS, et al, 2006: New trends in diagnosis and treatment of chronic intestinal strongyloidiasis stercoralis in Egyptian patients. J. Egypt. Soc. Parasitol. 36, 3:827-44.

Mazyad, MAM, Morsy, TA, Habib, KSM, 1999: Vertebral unilocular hydatidosis in a shepherd and his wife. J. Egypt. Soc. Parasitol. 29, 2:547-50.

McCabe, RE, Oster, S, 1989: Current recommendation and future prospects in the treatment of toxoplasmosis. Drugs 38:973-6.

Miró, JM, Blanes, M, Norman, F, Martín-Dávila, P, 2012: Infections in solid organ transplantation in special situations: HIV-infection and immigration. Enferm. Infec. Microbiol. Clin. 30, 2:S76-85.

Montoya, JG, Liesenfeld, O, 2004: Toxoplas- mosis. Lancet 363, 9425:1965-76.

Morgan-Ryan, UM, Fall, A, Ward, LA, et al, 2002: Cryptosporidium hominis n. sp. (Apicomplexa: Cryptosporidiidae) from Homo sapiens. J. Eukaryot. Microbiol. 49:433-9.

Morsy, TA, 1997: Visceral leishmaniasis with special reference to Egypt (Rev-iew and Comment). J. Egypt. Soc. Parasitol. 27, 2:373-96.

Musher, DM, Musher, BL, 2004: Contagious acute gastrointestinal infections. N. Engl. J. Med. 351: 2417-22.

Mussini, C, Pezzott, P, Govoni, A, et al, 2000: Discontinuation of primary prophylaxis for Pneumocystis carinii pneumonia and toxoplasmic encephalitis in human immunodeficiency virus type-1-infected patients: Changes in opportunisitic prophylaxis study. J. Infect. Dis. 181:1635-9. Nucci, M, Portugal, R, Pulcheri, W, et al, 1995: Strongyloides in patients with hematological malignancies. Clin. Infect. Dis. 21:675-8.

O'Brien, W, 1975: Intestinal malabsorption in acute infection with $S$. stercoralis. Trans. R. Soc. Trop. Med. Hyg., 69: 69-77.

Oksenhendler, E, Cadranel, J, Sarfati, C, et al, 1990: Toxoplasma gondii pneumonia in patients with acquired immunodeficiency syndrome. Am. J. Med. 88:18-21.

Paquet, C, Yudin, MH, 2018: No. 285-toxoplasmosis in pregnancy: Prevention, screening, and treatment. J. Obstet. Gynaecol 40, 8:e687-93.

Pedrosa, I, Saíz, A, Arrazola, J, Ferreirós, J, Pedrosa, CS, 2000: Hydatid disease: Radiologic and pathologic features and complications. Radiographics 20, 3:795-817.

Percipalle, M, Salvaggio, A, Pitari, GM, Giunta, RP, Aparo, A, et al, 2021: Edible insects \& Toxoplasma gondii: Is it something we need to be concerned about? J. Food Prot. 84, 3:437-41.

Polat, P, Kantarci, M, et al, 2003: Hydatid disease from head to toe. RadioGraphics 23:475-94. Pomeroy, C, Filice, GA, 1992: Pulmonary toxoplasmosis, a review. Clin. Infect. Dis. 14:863-6. Pozio, E, 1991: Current status of food-borne parasitic zoonoses in Mediterranean \&African regions. Southeast Asian J. Trop. Med. Publ. Hlth. 22:S85-7.

Pugin, J, Vanhems, P, Hirschel, B, et al, 1992: Extreme elevations of serum lactic dehydrogenase differentiating pulmonary toxoplasmosis from Pneumocystis pneumonia. N. Engl. J. Med. 326:1226-9.

Repetto, SA, Ruybal, P, Batalla, E, López, C, Fridman, $\mathrm{V}$, et al, 2018: Strongyloidiasis outsi- 
de endemic areas: Long-term parasitological and clinical follow-up after ivermectin treatment. $\mathrm{Cl}$ in. Infect. Dis. 66, 10:1558-65.

Robinson, G, Elwin, K, Chalmers, RM, 2008: Unusual Cryptosporidium genotypes in human cases of diarrhea. Emerg. Infect. Dis. 14:1800-4. Sabry, AA, Morsy, ATA, Morsy, TA, 2012: Zoonosis from dogs with special reference to Egypt. J. Egypt. Soc. Parasitol. 42, 3:583-604.

Sabry, AA, Fouad, MAH, Morsy, ATA, 2013: Zoonosis from cats: With special reference to Egypt. J. Egypt. Soc. Parasitol. 43, 2:429-46.

Saleh, AMA, Al-Agroudi, MA, Morsy, TA, 2016: Occupational, nosocomial or hospital acquired toxoplasmosis. J. Egypt. Soc. Parasitol. 46, 2:407-18.

Saleh, AMA, Ali, HA, Ahmed, SAM, Hosny, S M, Morsy, TA, 2014: Screening of Toxoplasma gondii infection among childbearing age females and assessment of nurses' role in prevention and control of toxoplasmosis. J. Egypt. Soc. Parasitol. 44, 2:329-42.

Sarkari, B, Rezaei, Z, 2015: Immunodiagnosis of human hydatid disease: Where do we stand? Wld, J. Methodol. 5, 4:185-95.

Sarwat, MA, Ahmed, AB, Zamzami, OM, Fawzy, AF, Morsy, TA, 1993: Toxoplasma gondii in Saudi blood donors: A serological study by 3 tests. J. Egypt. Soc. Parasitol. 23, 3:751-7.

Satoh, M, Kiyuna, S, Shiroma, Y, et al, 2003: Predictive markers for development of stronglyoidiasis in patients infected with both Strongyloides stercoralis and HTLV-1. Clin. Exp. Immunol. 133:391-6.

Sayek, I, Tirnaksiz, MB, Dogan, R, 2004: Cystic hydatid disease: current trends in diagnosis and management. Surg. Today 34, 12:987-96

Schwartz, SI, 1994: Liver. In: Principles of Surgery; Schwartz, SI, Shires, GT, et al, $6^{\text {th }}$ ed.; New York, McGraw-Hill, Inc.

Shamsuzzaman, SM, Hashiguchi， Y, 2002: Thoracic amebiasis. Clin Chest Med. 23 2:47992

Sharma, A, Sengupta, P, Mondal, S, Raychaudhuri, G, 2012: Hydatid cyst of ovary mimicking ovarian neoplasm with its imprint cytology. Am. J. Case Rep. 13:276-8.

Skalski, JH, Limper, AH, 2016: Fungal, viral, and parasitic pneumonias associated with human immunodeficiency virus. Semin. Respir. Crit. Care Med. 37, 2:257-66.

Song, JU, Um, SW, Koh, WJ, Suh, G, Chung, M, et al, 2011: Pulmonary paragonimiasis mimi- icking lung cancer in a tertiary referral centre in Korea. Int. J. Tuberc. Lung Dis. 15, 5:674-9.

Sponseller, J, Griffiths, J, Tripuri, S, 2014: The evolution of respiratory cryptosporidiosis: Evidence for transmission by inhalation. Clin. Microbiol. Rev. 27, 3:575-86

Taylor, WRJ, White, NJ, 2002: Malaria and the lung. Clin. Chest. Med. 23, 2:457-68.

Teixidor, HS, Godwin, TA, Ramirez, EA, 1991: Cryptosporidiosis of the biliary tract in AIDS. Radiology 180:51-8.

Thapa, B, Sapkota, R, Kim, M, Barnett, SA, Sayami, P, 2018: Surgery for parasitic lung infinfestations: Roles in diagnosis and treatment. J.

Thorac. Dis. 2018 10, 28:S3446-57

Temiz, A, Albayrak, Y, Akalp, Sö, Yalçın, A, Albayrak, A, 2017: Breast recurrent hydatid cyst disease. Chirurgia (Bucur). 112, 4:482-5.

Torres, JR, Isturiz, R, Murillo, J, et al, 1993: Efficacy of ivermectin in the treatment of Strongyloides complicating AIDS. Clin. Infect. Dis. 17:900-6.

Turkyilmaz, Z, Sonmez, K, Karabult, R, Demiroglari, B, Gol, H, et al, 2004: Conservative surgery for treatment of hydatid cysts in children. Wld. J. Surg. 28:597-601.

UNAIDS, 2009: Annual Report towards Universal Access. http://data.unaids.org/pub/Report/jc Varatharajalu, R, Kakuturu, R, 2016: Strongyloides stercoralis: Current perspectives. Reports in Parasitology: 23. doi:10.2147/RIP.S75839

Vannier, E, Krause, PJ, 2012: Human babesiosis. N. Engl. J/ Med. 366, 25:2397-407.

Viney, ME, 2006: The biology and genomics of Strongyloides. Med. Microbiol. Immunol. 195: 49-54.

Walker, MD, 2018: Reducing the risk of zoonotic infection. Conserv. Land Manag. 16, 2:19-22. Wen, H, Vuitton, L, Tuxun, T, Li, J, et al, 2019: Echinococcosis: Advances in the $21^{\text {st }}$ Century. Clin. Microbiol. Rev. 32: e00075-18.

Wilson, ME, 1991: A World Guide to Infections, Diseases, Distribution, Diagnosis. NY, Oxford, Oxford University Press.

Wishahy, AO, Rifaat, MA, Morsy, TA, EI Naggar, BA, 1972: Toxoplasmosis in children with some neurological manifestations. J. Trop. Med. Hyg.75, 12:255-6, London.

Wołyniec, W, Sulima, M, Renke, M, DębskaŚlizień, A, 2018: Parasitic infections associated with unfavorable outcomes in transplant recipients. Medicina (Kaunas). 54, 2:27-31. 